\title{
Unsur Retorika Pada Novelet Wesel Pos Karya Ratih Kumala serta Relevansinya Sebagai Bahan Ajar SMK
}

\author{
Anah Mulyanah*, Sahlan Mujtaba, M. Januar Ibnu Adham \\ Universitas Singaperbangsa Karawang, Indonesia \\ *Coresponding Author: 1710631080016@student.unsika.ac.id
}

Article History:

Received 2021-12-25

Revised 2022-02-03

Accepted 2022-03-01

DOI:

10.31949/educatio.v8i1.1835

\begin{abstract}
Types of literary works are very diverse, one of which is a novel. The novel is written with a distinctive writing and delivery character so that language disclosure is needed as an instrument in communicating. This study aims to describe the rhetorical elements in the Wesel Pos novelet by Ratih Kumala and its relevance as teaching materials in Vocational High Schools. The method in this study used a qualitative descriptive method. The subject of the research is the novelet Wesel Pos by Ratih Kumala which describes the social reality of the city of Jakarta. The storytelling uses an interesting style of language or rhetorical elements to be discussed. The rhetorical elements contained in the novelet Wesel Pos by Ratih Kumala are divided into three parts, namely exposition, structural analysis and imagery. The figure of speech consists of rhetorical figure of speech, metaphorical figure of speech, metonymy figure of speech, and sarcasm figure of speech. Structural tactics consist of repetition and parallelism. While the imagery consists of visual imagery, auditory imagery, motion imagery, tactile and olfactory imagery. These three elements are characteristic of the author describing the story in a literary work. This can be used as teaching material that can be implemented for Vocational High Schools with KD. Analyzing Content and Language.

Keywords: teaching materials; novelettes; elements of rhetoric
\end{abstract}

\begin{abstract}
Abstrak
Jenis karya sastra sangat beragam, salah satunya novel. Novel ditulis dengan karakter penulisan dan penyampaian yang khas sehingga diperlukan pengungkapan bahasa sebagai instrumen dalam berkomunikasi Penelitian ini bertujuan untuk mendeskripsikan unsur retorika pada novelet Wesel Pos karya Ratih Kumala dan relevansinya sebagai bahan ajar di Sekolah Menengah Kejuruan. Metode pada penelitian ini menggunakan metode deskriptif kualitatif. Subjek penelitiannya berupa novelet Wesel Pos Karya Ratih Kumala yang menggambarkan realitas sosial kota Jakarta. Pengisahannya menggunakan gaya bahasa atau unsur retorika yang menarik untuk diperbincangkan. Unsur retorika yang terkandung pada novelet Wesel Pos karya Ratih Kumala terbagi menjadi tiga bagian yaitu pemajasan, penyiasatan struktur dan citraan. Pemajasan terdiri dari majas retorika, majas metafora, majas metonimia, dan majas sarkasme. Penyiasatan struktur terdiri dari repetisi dan paralelisme. Sedangkan citraan terdiri dari citraan penglihatan, citraan pendengaran, citraan gerak, citraan rabaan dan penciuman. Ketiga unsur tersebut menjadi ciri khas pengarang menggambarkan cerita pada sebuah karya sastra. Hal ini dapat dijadikan sebagai bahan ajar yang dapat diimplementasikan untuk Sekolah Menengah Kejuruan dengan KD. Menganalisis Isi dan Kebahasaan.
\end{abstract}

Kata Kunci: bahan ajar; novelet; unsur retorika

\section{PENDAHULUAN}

Karya sastra merupakan bentuk karangan indah yang dihasilkan dari pengalaman pengarang. Pengalaman ini baik dirasakan secara langsung oleh pengarang sendiri maupun yang dialami orang lain sebagai acuan dalam pengimplementasiannya melalui sastra. Sastra ini sebagai media penggambaran gejala yang timbul di masyarakat dan dijadikan sebagai paradigma serta memberikan perhatian terhadap pengaruh yang terjadi. Jenis karya sastra sangat beragam termasuk novel, cerpen, puisi, novelet dan lain sebagainya. Berbicara 
novelet, masyarakat mengenal dengan sebutan novela. Istilah novella dan novelle mengandung pengertian yang sama dengan istilah Indonesia 'novelet' (Inggris novelette), yang berarti sebuah karya prosa fiksi yang panjangnya cukupan, tidak terlalu panjang, namun juga tidak terlalu pendek (Hermawan \& Shandi, 2019; Nurfadilla et al, 2020; Rasyidin et al, 2018). Menurut Nurgiyantoro (2015) bahwa novelet merupakan karya sastra yang lebih pendek daripada novel, tetapi lebih panjang daripada cerpen, katakanlah pertengahan di antara keduanya. Apabila dikuantitatifkan jumlah halaman sekitar 60 sampai 100 halaman. Sedangkan waktu membaca per satu novelet selesai dibaca dalam sekali duduk berkisar 1-2 jam.

Novelet dapat ditulis oleh pengarang dengan karakter penulisan dan penyampaian yang khas. Dalam hal ini, maka diperlukan pengungkapan bahasa sebagai instrumen dalam berkomunikasi. Sesuai dengan pandangan Nurgiyantoro (2015) bahwa bahasa merupakan sarana pengungkapan sastra yang mengemban fungsi utamanya, yaitu fungsi komunikatif. Apa pun yang akan dikatakan pengarang atau sebaliknya ditafsirkan oleh pembaca, mau tidak mau harus bersangkut-paut dengan bahasa.

Peneliti sebagai pembaca tertarik untuk menafsirkan bahasa pada novelet yang dibaca. Selain menarik, bahasa menjadi pusat pertama cara berkomunikasi antar manusia satu dengan yang lainnya melalui pengungkapan kata yang sudah dimanipulasi pengarang. Sesuai dengan pandangan Fowler (Nurgiyantoro, 2015) struktur fiksi dan segala sesuatu yang dikomunikasikan senantiasa dikontrol langsung oleh manipulasi bahasa pengarang. Sehingga bahasa sastra dapat disiasati, dimanipulasi dan didayagunakan bahkan bersifat emotif dan konotatif dengan penampilan bahasa yang berbeda dengan bahasa nonsastra. Maka, perlu analisis lebih dalam terkait gaya bahasa. Gaya bahasa atau gaya dan nada menurut Wiyatmi (2009) merupakan gaya bahasa atau cara pengungkapan seorang yang khas bagi seorang pengarang. Gaya meliputi penggunaan diksi atau pilihan kata, imajeri (citraan), dan sintaksis (pilihan pola kalimat) (Cahyono et al, 2018; Warnaningrum \& Macaryus, 2015). Sedangkan nada berhubungan dengan pilihan gaya untuk mengekspresikan sikap tertentu. Gaya dan nada ini biasa digunakan pengarang untuk mengekspresikan narasi, atau sikap tertentu.

Unsur gaya bahasa dilakukan dengan menggabungkan antara pembagian unsur menurut (Leech \& Short, 2007; Nurgiyantoro, 2015) terdapat tiga jenis, yaitu unsur leksikal, unsur gramatikal, dan unsur retorika. Dari ketiga dipilih salah satunya untuk memfokuskan peneliti menganalisis bahasa, yaitu unsur retorika. Retorika merupakan salah satu penggunaan bahasa melalui bentuk yang berupa pemajasan, penyiasatan struktur dan citraan. Jenis unsur retorika di antaranya (1) pemajasan adalah teknik pengungkapan bahasa, penggayabahasaan yang maknanya tidak menunjuk makna harfiah, tetapi makna yang tersirat. (2) penyiasatan struktur adalah gaya pengarang yang dapat menggabungkan efek retoris dan pemajasan. Ada macam penyiasan struktur seperti repetisi, anafora, paralelisme, antitesis, polisindenton dan asindenton, aliterasi, klimaks dan antiklimaks. Sedangkan (3) citraan adalah penggunaan kata-kata yang mampu membangkitkan tanggapan indra dalam cerita. Citraan ini meliputi lima unsur seperti penglihatan, pendengaran, gerak, rabaaan, dan penciuman (Leech \& Short, 2007; Nurgiyantoro, 2015).

Peneliti akan menganalisis ketiga gaya bahasa tersebut dengan menyajikan kutipan yang ada di novelet dan mengelompokkan berdasarkan bagiannya. Kajian unsur retorika juga telah banyak dilakukan dalam penelitian-penelitian sebelumnya, diantaranya penelitian Eligia et al. (2015), Marpaung (2015), dan Richardo \& Syam (2014). Adapun analisis pada penelitian ini menggunakan karya sastra berupa novelet Wesel Pos karya Ratih Kumala sebagai subjek penelitian. Karya sastra ini dapat dikategorikan sebagai novelet dengan melihat karakteristiknya. Dilihat dari jumlah ketebalannya yang berkisar 100 halaman dan isinya lebih pendek dibanding novel dan lebih panjang dibanding cerpen. Novelet ini juga salah satu di antara novel lainnya yang memiliki gaya kepengarangan yang khas. Ratih Kumala dalam novelet Wesel Pos menggambarkan realitas sosial kota Jakarta dengan berbagai persoalan yang menyertainya. Bahasa yang digunakan Ratih pada novelet disesuaikan dengan situasi dan kondisi kota Jakarta pada masyarakat menengah ke bawah, serta dibumbui dengan bahasa yang estetis.

Keterbatasan bahan ajar dalam pemahaman untuk menganalisis kebahasaan berkaitan dengan materi gaya bahasa pada novel sering ditemukan di sekolah. Hal ini, memerlukan penangan yang dapat dilakukan yaitu dengan adanya kerja sama antar ilmu pengetahuan melalui pembelajaran sastra. Salah satu jalan untuk mengatasi pengetahuan gaya bahasa pada novelet Wesel Pos karya Ratih Kumala dapat dijadikan sebagai bahan 
ajar yang tidak hanya menjelaskan unsur pemajasannya saja tetapi dapat dikembangkan dengan unsur penyiasatan struktur dan citraan.

Bahan ajar adalah seperangkat materi ajar yang akan diaplikasikan kepada peserta didik sebagai bahan untuk kegiatan belajar mengajar. Menurut Prastowo (2015) bahan ajar merupakan segala bahan (baik informasi, alat maupun teks) yang disusun secara sistematis, yang menampilkan sosok utuh dari kompetensi yang akan dikuasai peserta didik dan digunakan dalam proses pembelajaran dengan tujuan perencanaan dan penelaahan implementasi pembelajaran. Bahan ajar menurut bentuknya, dibedakan menjadi empat macam, yaitu bahan ajar cetak, bahan ajar dengar, bahan ajar pandang dengar, dan bahan ajar interaktif (Prastowo, 2016). Peneliti memilih bahan ajar berupa bahan cetak. Bahan cetak (printed), yakni sejumlah bahan yang disiapkan dalam kertas, yang dapat berfungsi untuk keperluan pembelajaran atau penyampaian informasi (Kemp \& Dayton, 1985; Prastowo, 2016).

Menurut Prastowo (2016) beberapa bentuk bahan ajar cetak, di antaranya handout, buku, modul, LKS, brosur, leaflet, wallchart, dan foto/gambar. Dari berbagai macam bentuk bahan ajar cetak, penelitian dalam analisis ini menghasilkan bahan ajar berupa handout untuk Sekolah Menengah Kejuruan kelas XII semester II. Handout adalah selembar (atau beberapa lembar) kertas yang berisi tugas atau tes yang diberikan pendidik kepada peserta didik (Alam \& Puspasari, 2019; Nuroso \& Khoiri, 2015). Tujuan pembuatan bandout untuk memperlancar dan membantu peserta didik sebagai pegangan untuk mendapatkan informasi atau materi yang diajarkan (Fitri, 2017). Bahan ajar bersumber dari literatur yang relevan sesuai kompetensi dasar untuk memudahkan saat proses pembelajaran. Penelitian ini diharapkan tidak semata-mata karena tujuan silabus yang sesuai saja, tetapi juga karena untuk mengetahui karakter pengarang dalam mengungkapkan bahasanya dalam sebuah karya sastra.

Berdasarkan pemaparan di atas, penelitian ini bertujuan untuk mendeskripsikan unsur retorika yang terkandung pada novelet Wesel Pos Karya Ratih Kumala. Penelitian ini diharapkan bermanfaat hasilnya sebagai bahan ajar di SMK kelas XII semester 2 pada KD. Menganalisis isi dan kebahasaan novel.

\section{METODE PENELITIAN}

Penelitian ini memerlukan metode yang akan digunakan sebagai langkah yang dilakukan secara berurutan dalam sebuah penelitian. Menurut Wiradi (dalam Arifin, 2017: 40), bahwa metode adalah seperangkat langkah (apa yang harus dikerjakan) yang tersusun secara sistematis (urutannya logis). Langkah yang diambil bertujuan untuk menganalisis unsur retorika pada novelet Wesel Pos karya Ratih Kumala sebagai bahan ajar di Sekolah Menengah Kejuruan. Metode penelitian ini menggunakan metode gabungan yang saling berkesinambungan antara satu dengan yang lainnya yaitu deskriptif analisis. Sedangkan jenis penelitian ini menggunakan penelitian kualitatif yang menghasilkan penemuan-penemuan yang tidak dapat dicapai dengan menggunakan prosedur statistik, tetapi adanya pemahaman yang dalam terhadap objek yang dikaji.

Sumber data dalam penelitian ini menggunakan sumber data primer dan sumber data sekunder. Sugiyono berpendapat (2018) sumber primer adalah sumber data yang langsung memberikan data kepada pengumpul data, dan sumber data sekunder merupakan sumber yang tidak langsung memberikan data pada pengumpul data, misalnya lewat orang atau lewat dokumen. Sumber data primer atau subjek penelitian sebagai pokok pembahasan sangat diperlukan untuk menganalisis. Sumber data primer tersebut berupa karya fiksi yaitu novelet Wesel Pos karya Ratih Kumala. Novelet ini cetakan pertama Juni 2018 yang diterbitkan oleh Gramedia Pustaka Utama, Jakarta dengan ketebalan 100 halaman. Sedangkan sumber data sekunder berupa dokumen seperti buku, jurnal, surat kabar, internet dan berbagai sumber lainnya yang berkaitan dengan objek penelitian yaitu unsur retorika.

Teknik pengumpulan data dalam penelitian ini adalah studi pustaka. Peneliti melakukan penelaahan buku sekaligus mencari informasi yang dikumpulkan dengan tiga teknik. Teknik tersebut digunakan dalam pengumpulan data yaitu mulai dari teknik baca, simak dan catat. Pertama, peneliti membaca novelet Wesel Pos karya Ratih Kumala secara menyeluruh dan membaca berbagai informasi di internet atau buku berdasarkan 
teori yang berkaitan dengan analisis. Kedua, pahami data-data hasil dari membaca. Ketiga, catat poin penting dari hasil membaca dan menyimak untuk mengumpulkan data yang akan dijadikan bahan penelitian.

Berdasarkan penelitian pada novelet Wesel Pos karya Ratih Kumala dibutuhkan instrumen penelitian untuk menganalisis data yang akan diteliti. Hal ini, peneliti bertugas untuk mengumpulkan data, menganalisis, dan menghasilkan penelitian. Penelitian yang akan dilakukan dapat dilakukan tiga teknik dalam menganalisis data. Baik mereduksi data, menyajikan data dan menarik sebuah kesimpulan. Ketiga tahapan ini dapat dilakukan dan saling berkesinambungan untuk menyelesaikan suatu rumusan masalah.

\section{HASIL DAN PEMBAHASAN}

Pada bagian hasil dan pembahasan, peneliti lebih awal melakukan analisis unsur retorika. Unsur retorika yang terdiri dari pemajasan, penyiasatan struktur dan citraan. Retorika adalah keterampilan pemakaian bahasa atau cara pengungkapan pengarang melalui pemilihan kata-kata untuk mengendalikan sebuah cerita. Ratih Kumala menggunakan bahasa sehari-hari untuk berinteraksi di lingkungan sosial di Kota Jakarta. Gaya bahasa ini cukup sederhana dan mudah dipahami. Selain itu pemajasan, penyiasatan dan citraan pada novelet Wesel Pos karya Ratih Kumala dijelaskan sebagai berikut.

1. Unsur Retorika

a. Pemajasan

Pemajasan merupakan teknik dalam pengungkapan bahasa yang memiliki makna yang tersirat di dalamnya. Majas yang terdapat pada novelet Wesel Pos karya Ratih Kumala diantaranya majas retorika, metafora, metonimia, dan sarkasme. Majas retorika merupakan majas yang menggunakan kalimat tanya yang tidak memerlukan jawaban. Kalimat tanya ini sebatas penegasan. Hal ini dibuktikan pada kutipan berikut.

"Kamu lugu atau naif? Penjahat itu enggak melulu harus laki-laki, enggake melulu barus preman. Ibu-ibu penjahat juga banyak.” (Kumala, 2018: 11)

Pada kutipan di atas dapat dikategorikan sebagai majas retorika. Kalimat tanya yang menunjukkan karakter seseorang tidak memerlukan jawaban.

Majas metafora merupakan majas yang membandingkan dua hal yang berbeda namun memiliki makna yang sama. Hal ini dibuktikan dengan kutipan berikut.

"Maudy melempar senyum ke Fabri, matanya berbinar ketika melihat pemuda itu. Tapi tak. lama, senyumnya memudar, saat melihat Elisa di belakang Fabri." (Kumala, 2018: 38)

Pada kutipan di atas dapat dikategorikan sebagai majas metafora yang terdapat kata berbinar yaitu sorotan senang, tapi dibandingkan dengan kata memudar atau sorotan tidak senang. Hal ini dipusatkan pada kata tapi.

Majas metonimia merupakan majas yang menggunakan kata lain misalnya merek suatu produk. Hal ini dibuktikan pada kutipan di bawah.

"Polisi dihadapanny memberikan air minum Aqua gelas." (Kumala, 2018: 14)

Pada kutipan di atas dapat dikategorikan sebagai majas metonimia, dilihat dari kata Aqua. Maksud kata Aqua menunjukkan sebuah merek air mineral.

Majas sarkasme merupakan majas yang disampaikan dengan kata-kata kasar, biasa seperti hujatan atau ancaman. Hal ini dibuktikan dengan kutipan berikut.

"Lo, anterin ini barang, kalo enggak... pacar lo gue sikat. Paham?" (Kumala, 2018: 83)

Pada kutipan di atas dapat dikategorikan sebagai majas sarkasme, terdapat kata sikat yang artinya akan mendapat ancaman untuk melumpuhkan seseorang apabila tidak mengikuti perintah.

b. Penyiasatan Struktur

Penyiasatan struktur ini melihat bagaimana pengarang menggunakan gaya bahasa yang sengaja disiasati. Penyiasatan struktur pada novelet Wesel Pos, di antaranya repetisi, dan paralelisme. Repetisi merupakan penyiasatan struktur yang memuat perulangan kata. Hal ini dibuktikan dengan kutipan berikut.

"Hari ini Jakarta melumpubkan Fahri, seperti balnya Ikbal dan itu berarti juga melumpubkan Elisa."

(Kumala, 2018: 98) 
Pada kutipan di atas dapat dikategorikan sebagai repetisi, karena ada kata perulangan melumpubkan. Kata melumpuhkan pada kalimat ini mengungkapkan bahwa Ikbal, Fahri, dan Elisa pada akhirnya tumbang oleh berbagai persoalan. Kata melumpubkan digunakan untuk mempertegas kata sebelumnya.

Paralelisme merupakan penyiasatan struktur dengan mengulang kata yang memiliki maksud yang sama. Hal ini dibuktikan dengan kutipan berikut.

"Dia bisa membeli TV flat 32 inch, membeli kulkeas..." (Kumala, 2018: 69)

Pada kutipan pertama dapat dikategorikan sebagai paralelisme, karena ada kata perulangan membeli yang maknanya sama mendapatkan TV dan kulkas dengan cara membelinya. Adapun kutipan yang masih menunjukkan jenis paralelisme, sebagai berikut.

“... mengirim kado untuk keponakan barunya, juga mengirim uang untuk Elisa." (Kumala, 2018: 69)

Pada kutipan kedua masih berhubungan dengan kutipan pertama yang dapat dikategorikan sebagai paralelisme. Kata mengirim di sini memiliki makna sama yaitu menyampaikan sesuatu. Meskipun dalam bentuk yang berbeda, yang satu dalam bentuk kado atau barang dan yang satu lagi dalam bentuk uang.

c. Citraan

Citraan ini bagaimana pengarang menggunakan kata-kata yang dapat membangkitan indra baik penglihatan, pendengaran, gerak, rabaan dan penciuman. Citraan penglihatan adalah citraan yang dihasilkan indera penglihatan yaitu mata. Berikut bukti kutipan citraan penglihatan pada novelet Wesel Pos karya Ratih Kumala.

"Elisa memandang gedung itu, jejeran jemuran bertingkat-tingkat berkibar-kibar. Tidak Cuma baju dan celana atau rok, ada juga yang menjemur kasur. Gantungan jemuran memutar terlibat di sana-sini, kebanyakan difungsikan menjemur baju bayi, beha, celana dalam dan kaos kaki." (Kumala, 2018: 27)

Pada kutipan pertama dapat dikategorikan sebagai citraan penglihatan. Di mana Ratih menunjukkan pada tokoh Elisa yang sedang memandang kondisi rusun. Elisa menggunakan indera penglihatannya dengan memandang berbagai jemuran yang terpampang di mana-mana.

"Si sopir angkot melihat uang itu, membesarkan volume musik, lalu tancap gas tanpa menunggu penumpang lain” (Kumala, 2018: 94)

Pada kutipan kedua dapat dikategorikan sebagai citraan penglihatan. Di mana Ratih menunjukkan pada tokoh sopir angkot yang sedang melihat uang. Uang sebagai alat transaksi yang berwujud dan dapat dilihat oleh indera penglihatan. Digambarkan supir dengan giat bekerja setelah melihat uang yang didapatnya.

Adapun citraan pendengaran adalah citraan yang dihasilkan indera pendengaran yaitu telinga. Berikut bukti kutipan citraan pendengaran pada novelet Wesel Pos karya Ratih Kumala.

"Selurub orang di lantai tujuh penasaran keluar unitnya manakala mendengar tangisan si wanita simpanan yang sesenggukan." (Kumala, 2018: 47)

Pada kutipan di atas dapat dikategorikan sebagai citraan pendengaran. Di mana Ratih menunjukkan pada tangisan wanita simpanan. Tangisan ini menimbulkan suara yang dapat didengar oleh indera pendengaran. Tangisan ini menjadi pusat perhatian bagi warga rusun.

Adapun citraan gerak adalah citraan yang menggambarkan sesuatu yang bergerak dan dapat dilihat. Berikut bukti kutipan citraan gerak pada novelet Wesel Pos karya Ratih Kumala.

"Dia membersibkan kuburan yang terlihat tak pernah seorang pun menengokinya. Rumput liar tumbuh di sana-sini." (Kumala, 2018: 52)

Pada kutipan di atas dapat dikategorikan sebagai citraan gerak. Di mana Ratih menunjukkan pada tokoh Elisa yang sedang membersihkan kuburan. Membersihkan merupakan kata kerja yang dapat memberikan pandangan kepada pembaca bahwa Elisa sedang gerak dengan membersihkan rumput liar.

Adapun citraan rabaan dan penciuman adalah citraan yang melibatkan hal-hal yang dirasakan. Citraan ini dapat melalui rabaan berupa sentuhan dan penciuman yaitu dengan alat pencium berupa hidung. Berikut bukti kutipan citraan gerak pada novelet Wesel Pos karya Ratih Kumala.

“... Aroma kencing, keringat, vagina, pejuh, muntah, dan sakaw bercampur begitu memasuki gang." (Kumala, 2018: 58) 
Pada kutipan di atas dapat dikategorikan sebagai citraan penciuman. Di mana Ratih menunjukkan pada berbagai aroma tidak sedap di area gang. Timbulnya aroma ini dapat dicium oleh indera penciuman yaitu hidung.

Tabel 1. Kartu Data Unsur Retorika pada Novelet Wesel Pos Karya Ratih Kumala

\begin{tabular}{|c|c|c|}
\hline No & $\begin{array}{l}\text { Jenis Unsur } \\
\text { Retorika }\end{array}$ & Jenis dan Kutipan \\
\hline 1. & Pemajasan & $\begin{array}{l}\text { a. Majas Retorika } \\
\text { "Kamu lugu atau naif? Penjahat itu enggak melulu harus laki- } \\
\text { laki, enggak melulu harus preman. Ibu-ibu penjahat juga } \\
\text { banyak." } \\
\text { b. Majas Metafora } \\
\text { "Maudy melempar senyum ke Fahri, matanya berbinar ketika } \\
\text { melihat pemuda itu. Tapi tak lama, senyumnya memudar, saat } \\
\text { melihat Elisa di belakang Fahri." } \\
\text { c. Majas Metonimia } \\
\text { "Polisi dihadapannya memberikan air minum Aqua gelas." } \\
\text { d. Majas Sarkasme } \\
\text { "Lo, anterin ini barang, kalo enggak... pacar lo gue sikat. } \\
\text { Paham?" }\end{array}$ \\
\hline
\end{tabular}

(Kumala, 2018: 14)

(Kumala, 2018: 83)

2. Penyiasatan a. Repetisi

Struktur "Hari ini, Jakarta sudah melumpuhkan Fahri, seperti halnya

(Kumala, 2018: 98) melumpuhkan Ikbal, dan itu berarti juga melumpuhkan Elisa."

b. Paralelisme

"Dia bisa membeli TV flat 32 inch, membeli kulkas..."

“... mengirim kado untuk keponakan barunya, juga mengirim (Kumala, 2018: 69)

3. Citraan a. Citraan Penglihatan

"Elisa memandang gedung itu, jejeran jemuran bertingkattingkat berkibar-kibar. Tidak Cuma baju dan celana atau rok, ada juga yang menjemur kasur. Gantungan jemuran memutar terlihat di sana-sini, kebanyakan difungsikan menjemur baju bayi, beha, celana dalam dan kaos kaki."

"Si sopir angkot melihat uang itu, membesarkan volume musik, lalu tancap gas tanpa menunggu penumpang lain."

(Kumala, 2018: 94)

b. Citraan Pendengaran

"Seluruh orang di lantai tujuh penasaran keluar unitnya (Kumala, 2018: 47) manakala mendengar tangisan si wanita simpanan yang sesenggukan."

c. Citraan Gerak

"Dia membersihkan kuburan yang terlihat tak pernah seorang pun menengokinya. Rumput liar tumbuh di sana-sini."

(Kumala, 2018: 52)

d. Citraan Rabaan dan Penciuman

“... Aroma kencing, keringat, vagina, pejuh, muntah, dan (Kumala, 2018: 58) sakaw bercampur begitu memasuki gang."

Dapat disimpulkan bahwa unsur retorika pada novelet Wesel Pos karya Ratih Kumala terdapat tiga jenis yaitu pemajasan, penyiasatan struktur dan citraan. Hal yang sam juga ditemukan dalam penelitian Eligia et al. (2015), Marpaung (2015), dan Richardo \& Syam (2014). Pada novel ini, Ratih menggambarkan penceritaan dengan menggunakan bahasa sehari-hari yang mudah dipahami untuk berinteraksi di sosial kota Jakarta. 
Diselipkan juga dengan bahasa gaul sebagai simbol pergaulan di Jakarta seperti “lo" sebutkan kamu. Selain itu, terdapat majas retorika, majas metafora, majas metonimia, dan majas sarkasme. Penyiasatan struktur terdapat repetisi dan paralelisme. Sedangkan citraan berkaitan dengan citraan penglihatan, citraan pendengaran, citraan gerak, citraan rabaan dan penciuman. Itulah kekhasan Ratih dalam mentransfer bahasa dalam karyanya melalui kutipan yang sudah ditemukan pada saat pengumpulan data.

\section{Relevansinya sebagai Bahan Ajar di Sekolah Menengah Kejuruan}

Bahan ajar yang dapat diterapkan untuk tingkat Sekolah Menengah Kejuruan kelas XII semester 2 pada Kompetensi Dasar 3.9 Menganalisis Isi dan Kebahasan berupa handout yaitu seperangkat bahan yang berisi tugas atau tes yang diberikan pendidik kepada peserta didik. Tujuan pembuatan handout untuk memperlancar dan membantu peserta didik sebagai pegangan untuk mendapatkan informasi atau materi novelet. Bahan ajar ini dapat bersumber dari literatur yang relevan sesuai kompetensi dasar untuk memudahkan saat proses belajar.

Beberapa informasi yang tertuang pada bahan ajar yang akan diterapkan yaitu materi tentang pengertian novelet, jenis unsur retorika, tugas, dan penilaian. Berdasarkan hasil penelitain terkait penemuan unsur retorika pada novelet Wesel Pos dengan mencantumkan kutipan sesuai jenis gaya bahasa pengarang, dapat disimpulkan bahwa Ratih Kumala menggunakan bahasa sederhana atau sehari-hari, sehingga memudahkan peserta didik untuk menelisik maksud yang ingin disampaikan. Selain itu, novelet ini menggunakan bahasa estetis yang dapat dikategorikan ke dalam jenis unsur retorika untuk dianalisis kebahasaannya. Bahasa pengarang juga dekat dengan cara orang-orang Jakarta berinteraksi, hal ini juga sebagai pembelajaran bahwa setiap kota memiliki ciri khas berbahasa yang beragam.

\section{KESIMPULAN}

Gaya yang digunakan Ratih Kumala pada novelet Wesel Pos yaitu dengan bahasa sehari-hari untuk berinteraksi di lingkungan sosial di Kota Jakarta. Ratih menggunakan unsur retorika dalam novelet Wesel Pos dengan pemajasan, penyiasatan struktur dan citraan. Pemajasan yang ditemukan pada novelet Wesel Pos karya Ratih Kumala berupa majas retorika, majas metafora, majas metonimia, dan majas sarkasme. Penyiasatan struktur yang ditemukan berupa repetisi dan paralelisme. Sedangkan citraan berupa citraan penglihatan, pendengaran, gerak, rabaan dan penciuman.

Dari hasil analisis gaya bahasa dengan memfokuskan pada unsur retorika, maka relevansinya dapat berupa bahan ajar di Sekolah Menengah Kejuruan pada materi novel untuk menganalisis kebahasaannya. Bahan ajar ini berupa handout yang dapat diaplikasikan kepada peserta didik sebagai bahan dalam kegiatan belajar mengajar di semester 2 .

\section{DAFTAR PUSTAKA}

Alam, H., \& Puspasari, D. (2019). Pengembangan lembar kegiatan peserta didik berbasis model pembelajaran project based learning pada mata pelajaran kearsipan di SMK Negeri 1 Lamongan. Jurnal Pendidikan Administrasi Perkantoran 07 (03), 111-116.

Arifin, Z. (2017). Metode Penulisan Ilmiah. Tangerang: Pustaka Mandiri.

Cahyono, N., Andayani, A., \& Mujiyanto, Y. (2018). Analisis Stilistika Novel Dari Hari Ke Hari Karya Mahbub Djunaidi Dan Relevansinya Sebagai Materi Ajar Bahasa Indonesia Di Sekolah Menengah Atas. Basastra: Jurnal Bahasa, Sastra, dan Pengajarannya, 6(2), 140-148.

Eligia, H. W., Priyadi, A. T., \& Muzammil, A. R. U. (2015). Unsur retorika dalam kumpulan cerita pendek Celeng Satu Celeng Semua karya Triyanto Triwikromo. Jurnal Pendidikan dan Pembelajaran Khatulistiwa, 4(9).

Fitri, Y. (2017). Pengembangan Bahan Ajar Hand Out Statistik Dengan Menggunakan Pendekatan Inkuiri Di Fakultas Keguruan Dan Ilmu Pendidikan Universitas Ekasakti Padang. UNES Journal of 
Education, 1(4), 364-375.

Hermawan, D., \& Shandi, S. P. (2019). Pemanfaatan Hasil Analisis Novel Seruni Karya Almas Sufeeya sebagai Bahan Ajar Sastra di SMA. Metamorfosis $\mid$ Jurnal Bahasa, Sastra Indonesia dan Pengajarannya, 12(1), $11-20$.

Kemp, J. E., \& Dayton, D. K. (1985). Planning and producing instructional media. Harper \& Row.

Kumala, R. (2018). Wesel Pos. Jakarta: Gramedia Pustaka Utama

Leech, G. N., \& Short, M. (2007). Style in fiction: A linguistic introduction to English fictional prose (No. 13). Pearson Education.

Marpaung, S. M. (2013). Unsur Retorika Dalam Novel "Maestro" Karya Alex Suhendra (Tinjauan Stilistika). Jurnal Sasindo (Program Studi Sastra Indonesia FBS UNIMED), 2(2).

Nurfadilla, N., Rijal, S., \& Usman, M. (2020). Pengajaran Sastra Bahasa Jerman di Sekolah Menengah Atas (SMA). Interference: Journal of Language, Literature, and Linguistics, 1(2), 121-127.

Nurgiyantoro, B. (2015). Teori Pengkajian Fiksi. Yogyakarta: Gadjah Mada University Press.

Nuroso, H., \& Khoiri, N. (2015). Efektivitas Model Pembelajaran Cooperative Script Berbantuan Handout Pada Pokok Bahasan Besaran Dan Satuan Terhadap Kemampuan Berpikir Kritis Siswa Kelas X Sma Negeri 1 Gubug. Jumal Penelitian Pembelajaran Fisika, 6(2).

Prastowo, Andi. (2015) Panduan Kreatif Membuat Bahan Ajar Inovatif. Yogyakarta: Diva Press.

Ratna, N. K. (2015). Teori, Metode, dan Teknik Penelitian Sastra. Yogyakarta: Pustaka Pelajar

Rasyidin, U., Aziz, F. S., \& Firmansyah, D. (2018). Pengaruh Novel Dilan Terhadap Karakter Siswa Dilihat Dari Tokoh Dilan. Parole (Jurnal Pendidikan Bahasa dan Sastra Indonesia), 1(3), 257-266.

Richardo, A. A., \& Syam, C. (2014). Unsur Retorika Dalam Novel Tarian Bumi Karya Oka Rusmini. Jurnal Pendidikan dan Pembelajaran Khatulistiwa, 3(10).

Sidiq, U., \& Miftachul C. (2019). Metode Penelitian Kualitatif di Bidang Pendidikan. Ponorogo: VC. Nata Karya

Sugiyono. (2018). Metode Penelitian Kuantitatif, Kualitatif, dan R\&D. Bandung: Alfabeta

Warnaningrum, A., \& Macaryus, S. (2015). Gaya bahasa 10 geguritan dalam antologi Nurani Peduli karya Handoyo Wibowo. Caraka, 2(1), 133-150.Warsiman. (2017). Pengantar Pembelajaran Sastra: Sajian dan Kajian Hasil Riset. Malang: UB Press.

Wiyatmi. (2009). Pengantar Kajian Sastra. Yogyakarta: Pustaka Book Publisher

Wiyatmi. (2013). Sosiologi Sastra: Teori dan Kajian terhadap Sastra Indonesia. Yogyakarta: Kanwa Publisher 